\title{
Molecular typing and profiling of topoisomerase mutations causing resistance to ciprofloxacin and levofloxacin in Elizabethkingia species
}

\author{
Ming-Jr Jian ${ }^{1,2}$, Yun-Hsiang Cheng ${ }^{1,2}$, Cherng-Lih Perng ${ }^{1,2}$, Hung-Sheng Shang ${ }^{\text {Corresp. } 1,2}$ \\ ${ }^{1}$ Graduate Institute of Medical Science, National Defense Medical Center, Taipei, Taiwan \\ 2 Division of Clinical Pathology, Department of Pathology, Tri-Service General Hospital, National Defense Medical Center, Taipei, Taiwan \\ Corresponding Author: Hung-Sheng Shang \\ Email address: iamkeith@mail.ndmctsgh.edu.tw
}

Objectives. Several Elizabethkingia species often exhibit extensive antibiotic resistance, causing infections associated with severe morbidity and high mortality rates worldwide. In this study, we determined fluoroquinolone susceptibility profiles of clinical Elizabethkingia spp. isolates and investigated the resistance mechanisms.

Methods. In 2017-2018, 131 Elizabethkingia spp. isolates were recovered from specimens collected at tertiary care centers in northern Taiwan. Initial species identification using the Vitek MS system and subsequent verification by $16 \mathrm{~S}$ rRNA sequencing confirmed the presence of $E$. anophelis $(n=111), E$. miricola $(n=11)$, and E. meningoseptica $(n=9)$. Fluoroquinolone susceptibility was determined using the microbroth dilution method, and fluoroquinolone resistance genes were analyzed by sequencing.

Results. Among Elizabethkingia spp. isolates, $91 \%$ and $77 \%$ were resistant to ciprofloxacin and levofloxacin, respectively. The most prevalent alterations were two single mutations in GyrA, Ser83lle and Ser83Arg, detected in $76 \%$ of the isolates exhibiting fluoroquinolone MIC between 8 and $128 \mu \mathrm{g} / \mathrm{ml}$. Another GyrA single mutation, Asp87Asn, was identified in two quinolone-resistant $E$. miricola strains. None of the isolates had alterations in GyrB, ParC or ParE. We developed a high-resolution melting assay for rapid identification of the prevalent gyrA gene mutations. The genetic relationship between the isolates was evaluated by random amplified polymorphic DNA PCR that yielded diverse pulsotypes, indicating the absence of any temporal or spatial overlap among the patients during hospitalization.

Conclusions. Our analysis of fluoroquinolone-resistant Elizabethkingia spp. isolates provides information for further research on the variations of the resistance mechanism and potential clinical guidance for infection management. 
1 Molecular typing and profiling of topoisomerase mutations causing resistance to

2 ciprofloxacin and levofloxacin in Elizabethkingia species.

3

4 Ming-Jr Jian ${ }^{1,2}$, Yun-Hsiang Cheng ${ }^{1,2}$ Cherng-Lih Perng ${ }^{1,2}$, Hung-Sheng Shang ${ }^{1,2}$

5

$6{ }^{1}$ Graduate Institute of Medical Science, National Defense Medical Center, Taipei City, Taiwan

7 2Division of Clinical Pathology, Department of Pathology, Tri-Service General Hospital,

8 National Defense Medical Center, Taipei City, Taiwan

9

10 Corresponding author: Hung-Sheng Shang (E-mail: iamkeith@mail.ndmctsgh.edu.tw);

11 National Defense Medical Center, 325, Section 2, Cheng-Kung Road, Neihu 114, Taipei,

12 Taiwan, Republic of China.

13

14 Running title: Quinolone resistance in Elizabethkingia species

15

16

17

18

19

20 


\section{Abstract}

23 Objectives. Several Elizabethkingia species often exhibit extensive antibiotic resistance, causing

24 infections associated with severe morbidity and high mortality rates worldwide. In this study, we

25 determined fluoroquinolone susceptibility profiles of clinical Elizabethkingia spp. isolates and

26 investigated the resistance mechanisms.

27 Methods. In 2017-2018, 131 Elizabethkingia spp. isolates were recovered from specimens

28 collected at tertiary care centers in northern Taiwan. Initial species identification using the Vitek

29 MS system and subsequent verification by $16 \mathrm{~S}$ rRNA sequencing confirmed the presence of $E$.

30 anophelis $(\mathrm{n}=111)$, E. miricola $(\mathrm{n}=11)$, and E. meningoseptica $(\mathrm{n}=9)$. Fluoroquinolone

31 susceptibility was determined using the microbroth dilution method, and fluoroquinolone

32 resistance genes were analyzed by sequencing.

33 Results. Among Elizabethkingia spp. isolates, 91\% and 77\% were resistant to ciprofloxacin and

34 levofloxacin, respectively. The most prevalent alterations were two single mutations in GyrA,

35 Ser83Ile and Ser83Arg, detected in $76 \%$ of the isolates exhibiting fluoroquinolone MIC between

368 and $128 \mu \mathrm{g} / \mathrm{ml}$. Another GyrA single mutation, Asp87Asn, was identified in two quinolone-

37 resistant E. miricola strains. None of the isolates had alterations in GyrB, ParC or ParE. We

38 developed a high-resolution melting assay for rapid identification of the prevalent gyr $A$ gene 
39 mutations. The genetic relationship between the isolates was evaluated by random amplified

40 polymorphic DNA PCR that yielded diverse pulsotypes, indicating the absence of any temporal

41 or spatial overlap among the patients during hospitalization.

42 Conclusions. Our analysis of fluoroquinolone-resistant Elizabethkingia spp. isolates provides

43 information for further research on the variations of the resistance mechanism and potential

44 clinical guidance for infection management.

45

46 


\section{Introduction}

48 The genus Elizabethkingia has been recently revised to include several species based on whole-

49 genome sequencing analysis (Doijad et al. 2016; Nicholson et al. 2017). Elizabethkingia species

50 are non-motile, non-fastidious, and glucose-non-fermentative gram-negative bacilli (Janda \&

51 Lopez 2017). Three species, E. meningoseptica, E. miricola, and E. anophelis, are known to

52 cause diseases in humans (Green et al. 2008; Jean et al. 2014a; Lau et al. 2016b). Recent studies

53 suggest that certain strains causing sporadic cases of meningitis and bacteremia, previously

54 identified as E. meningoseptica, belong to E. anophelis (Chew et al. 2017; Lin et al. 2017).

55 Several outbreaks of E. anophelis-associated infections have been reported, including two

56 outbreaks in the U.S. Midwest in 2016 with 65 confirmed cases (Coyle 2017; Janda \& Lopez

57 2017). Elizabethkingia species also cause outbreaks in intensive care units as emerging

58 pathogens of nosocomial infections with a high mortality rate and severe morbidity in critically

59 ill patients (Jean et al. 2014a; Lau et al. 2016b; Opota et al. 2017; Shaohua et al. 2017). Because

60 of their ability to accumulate different resistance mechanisms and a growing number of more

61 vulnerable hosts, the prevalence of multidrug-resistant Elizabethkingia species has increased in

62 the past decades, limiting the options for treatment (Janda \& Lopez 2017; Jean et al. 2014b). For

63 instance, resistance to carbapenems is mediated by metallo- $\beta$-lactamases (Breurec et al. 2016;

64 Chen et al. 2017; Colapietro et al. 2016). A previous report indicated that fluoroquinolones are 
65 suitable for treating E. meningoseptica bacteremia (Huang et al. 2018), and empirical evidence

66 indicates that they are effective in treating E. anophelis and E. miricola infections (Coyle 2017;

67 Figueroa Castro et al. 2017; Green et al. 2008; Zdziarski et al. 2017). However, a detailed

68 analysis of fluoroquinolone-resistant Elizabethkingia spp. infections has not yet been performed.

69 Fluoroquinolones, such as ciprofloxacin (CIP) or levofloxacin (LVX), have two bacterial drug

70 targets, DNA gyrase and DNA topoisomerase IV (Khodursky et al. 1995; Kreuzer \& Cozzarelli

71 1979). Each enzyme is a heterotetramer, with gyrase composed of two GyrA and two GyrB

72 subunits and topoisomerase IV composed of two ParC and two ParE subunits. Mechanisms of

73 fluoroquinolone resistance include mutational alterations in drug target affinity, increased efflux

74 pump expression, and acquisition of resistance-conferring genes (Hooper \& Jacoby 2016). Single

75 amino acid changes in either gyrase or topoisomerase IV can cause quinolone resistance. In

76 gram-negative bacilli, mutations have been typically localized to the amino-terminal region of

77 the primary target, GyrA (Yoshida et al. 1990), a region conserved among all potential quinolone

78 targets. Mutations in these conserved regions of GyrB, ParC, and ParE are also known to confer

79 fluoroquinolone resistance, like the amino-terminal GyrA region (Heisig 1996; Yoshida et al.

80 1991). Accordingly, the genomic DNA regions encoding the conserved protein regions of GyrA,

81 GyrB, ParC, and ParE have been termed quinolone resistance-determining regions (QRDRs).

82 In this study, we aimed to assess the relationship between the quinolone-resistant phenotype of 
83 clinical Elizabethkingia spp. isolates in Taiwan and mutations in their DNA gyrase and DNA

84 topoisomerase IV genes. 


\section{Materials \& Methods}

\section{Bacterial isolates}

87 In 2017-2018, 131 isolates of Elizabethkingia spp. (E. anophelis, n=111; E. meningoseptica,

$88 \mathrm{n}=9 ;$ E. miricola, $\mathrm{n}=11$ ) were recovered by bacterial culture from respiratory tract, urine, catheter

89 tip, and blood specimens collected at the Tri-Service General Hospital (TSGH), tertiary care

90 centers in northern Taiwan. The species were initially identified using the Vitek MS system with

91 the IVD 3.0 database (bioMérieux, Mercy l'Etoile, France). Isolates identified as Elizabethkingia

92 species using a previously reported study (Cheng et al. 2018). Briefly, MALDI-TOF spectral

93 analysis software identified significant species-specific peaks to create reference masses for

94 efficient and accurate identification of Elizabethkingia spp.. All bacterial isolates were kept

95 frozen until used in this study.

96 Antimicrobial susceptibility

97 MIC of CIP and LVX were determined using the broth microdilution method. The

98 susceptibilities were evaluated according to guidelines published by the Clinical and Laboratory

99 Standards Institute (CLSI) including antibiotic-specific breakpoints (CIP: susceptible $\leq 1 \mu \mathrm{g} / \mathrm{ml}$,

100 resistant $\geq 4 \mu \mathrm{g} / \mathrm{ml} ;$ LVX: susceptible $\leq 2 \mu \mathrm{g} / \mathrm{ml}$, resistant $\geq 8 \mu \mathrm{g} / \mathrm{ml})$

101

102

\section{DNA extraction}


103 Genomic DNA was isolated using a previously reported protocol (Syn \& Swarup 2000). Briefly,

104 cellular lysis is achieved by a combination of EDTA/SDS detergent lysis and brief heat

105 treatment. An additional phenol/chloroform step further deproteinates the preparation yielding

106 DNA of good quality. Using a picodrop spectrophotometer, purified genomic DNA

107 concentrations were determined by measuring the optical density at $260 \mathrm{~nm}$, whereas the purity

108 was estimated by calculating the ratio of the optical densities measured at $260 \mathrm{~nm}$ and $280 \mathrm{~nm}$.

109 DNA samples were stored at $-20^{\circ} \mathrm{C}$ until PCR was performed.

110

111 Bacteria species identification by 16S rRNA sequencing

112 The microbial identification accuracy was verified by $16 \mathrm{~S}$ rRNA sequencing using a pair of

113 specific primers, 27F (5'-AGAGTTTGATCMTGGCTCAG-3') and 1492R (5'-

114 GGYTACCTTGTTACGACTT-3'), as previously described (Chang et al. 2014). DNA

115 sequencing were compared to reference sequences using the Basic Local Alignment Search Tool

116 (BLAST) of the National Center for Biotechnology Information database.

117

118 PCR and DNA sequencing of the topoisomerase gene

119 Isolates were screened for mutations in the $\operatorname{gyr} A$, gyrB, parC, or parE genes by PCR using

120 species-specific primers (Table 1). PCR products were sequenced for detection of nucleotide 
121 polymorphism. Primers were commercially synthesized by Genomics (New Taipei city, Taiwan).

122 The reaction mixture $(50 \mu \mathrm{l})$ contained $10 \mathrm{mM}$ Tris- $\mathrm{HCl}(\mathrm{pH} 7.5), 50 \mathrm{mM} \mathrm{KCl}, 1.5 \mathrm{mM} \mathrm{MgCl}$,

$1230.2 \mathrm{mM}$ dNTPs, $10 \mathrm{pmol}$ of the forward and reverse primer, $50 \mathrm{ng}$ template DNA, and $0.8 \mathrm{U}$ of

124 Taq DNA polymerase (Applied Biosystems, Foster City, CA). Amplification was carried out in a

125 ProFlex PCR thermal cycler (Applied Biosystems, Foster City, CA) with one initial denaturation

126 step of $2 \mathrm{~min}$ at $95^{\circ} \mathrm{C} ; 40$ cycles of a denaturing step of $15 \mathrm{sec}$ at $94^{\circ} \mathrm{C}$, an annealing step of 1

127 min at $48-50^{\circ} \mathrm{C}$ with corresponding genes, and an extension step of $1 \mathrm{~min}$ at $72^{\circ} \mathrm{C}$; and a final

128 elongation step of $5 \mathrm{~min}$ at $72^{\circ} \mathrm{C}$. All PCR products were processed for DNA sequencing

129 (Genomics, New Taipei city, Taiwan) with the same PCR primer sets. Sequencing results in

130 candidate genes from each isolate were compared with the respective reference sequences in the

131 GenBank database (NCBI reference sequences: E. anophelis, NZ_CP007547.1; E.

132

meningoseptica, NZ_CP016376.1; E. miricola, NZ_CP023746.1)

133

134 High-resolution melting (HRM) assay for gyr $A$ mutation screening

135 Three different reverse primers and one common forward primer with homology to

136 Elizabethkingia spp. gyrA gene were designed (Table 1). PCR amplification was performed

137 using the KAPA HRM FAST PCR Kit for preparing the following reaction: $20 \mu 1$ reaction mix

138 containing $1 \mu \mathrm{l}$ template DNA (10 ng), $8 \mu$ l PCR grade nuclease-free $\mathrm{H}_{2} \mathrm{O}, 10 \mu \mathrm{KAPA}$ HRM

139 FAST Master Mix, $2 \mu 125 \mathrm{mM} \mathrm{MgCl}_{2}$, and $0.5 \mu 1$ of forward/reverse primer mix (10 $\mu \mathrm{M}$ each).

140 The amplification and HRM curve analyses were conducted on a LightCycler 96 instrument 
141 (Roche, Manheim, Germany) using the following cycling conditions: initial activation at $95^{\circ} \mathrm{C}$

142 for $2 \mathrm{~min}, 40$ cycles at $95^{\circ} \mathrm{C}$ for $10 \mathrm{sec}$ and at $60^{\circ} \mathrm{C}$ for $30 \mathrm{sec}$. The post-PCR melting curve was

143 performed using temperatures between $65^{\circ} \mathrm{C}$ and $95^{\circ} \mathrm{C}$ in temperature increments of $0.3^{\circ} \mathrm{C}$.

144

145 RAPD-PCR and capillary gel electrophoresis analysis

146 RAPD-PCR was performed using primers (Table 1) described previously (Hsueh et al. 1996,

147 Chiu et al. 2000). The reaction mixture $(25 \mu \mathrm{l})$ contained $10 \mathrm{mM}$ Tris- $\mathrm{HCl}(\mathrm{pH} 7.5), 50 \mathrm{mM}$

$148 \mathrm{KCl}, 2.5 \mathrm{mM} \mathrm{MgCl}_{2}, 0.2 \mathrm{mM}$ dNTPs, 15 pmol of the RAPD primer, $50 \mathrm{ng}$ genomic DNA, and

1490.8 U of DyNAzyme II DNA polymerase (ABI, Thermo Fisher Scientific, Foster City, CA,

150 USA). For every sample, each RAPD reaction was performed at least twice for each DNA

151 extract. Amplification was carried out in a ProFlex PCR thermal cycler (Applied Biosystems,

152 Foster City, CA) with one initial denaturation step of 5 min at $95^{\circ} \mathrm{C} ; 40$ cycles of a denaturing

153 step of $1 \mathrm{~min}$ at $94^{\circ} \mathrm{C}$, an annealing step of $1 \mathrm{~min}$ at $36^{\circ} \mathrm{C}$, and an extension step of $2 \mathrm{~min}$ at

$15472^{\circ} \mathrm{C}$, and a final elongation step at $72^{\circ} \mathrm{C}$ for $8 \mathrm{~min}$.

155 After PCR amplification, the products were analyzed on Qsep100 DNA Analyzer (BiOptic,

156 Taiwan) according to the manufacturer's instructions. PCR fragments were applied into a

157 miniaturized single-channel capillary cartridge of the Qsep100 DNA-CE with separation buffer.

158 The run was performed using a high-resolution cartridge with a sample injection protocol of 8

$159 \mathrm{kV}$ for $10 \mathrm{~s}$ and separation at $5 \mathrm{kV}$ for $300 \mathrm{~s}$. The DNA alignment markers $(20 \mathrm{bp}, 1.442 \mathrm{ng} / \mu \mathrm{l}$,

160 and $5000 \mathrm{bp}, 1.852 \mathrm{ng} / \mu \mathrm{l})$ and the DNA size marker (50-3000 bp, $10.5 \mathrm{ng} / \mu \mathrm{l})$ were obtained

161 from BiOptic. Sample peaks were visualized using Q-Analyzer software (BiOptic).

162

163 Molecular pattern analysis

164 Isolates were categorized as identical, similar or unrelated according to their PCR banding 
165 patterns. The data were analyzed using GelCompar II software (Applied Maths NV, Belgium).

166 Dice similarity coefficients were calculated and clustering was done by unweighted pair group

167 mean association (UPGMA).

168

169 Data analysis

170 Statistical significance was determined using Student's t-test (GraphPad Prism). Differences were

171 considered statistically significant when $\mathrm{p}<0.05$. 


\section{Results}

174 CIP and LVX susceptibility profiles of Elizabethkingia spp. isolates and corresponding

175 resistance mutations

176 The 131 Elizabethkingia spp. isolates differed in their susceptibility to CIP and LVX (Fig. 1 and

177 Table 2); 91\% and 77\% were resistant to CIP and LVX, respectively. All E. meningoseptica

178 isolates were resistant to CIP, whereas $44 \%$ were resistant to LVX; $73 \%$ of the E. miricola

179 isolates were resistant to CIP and 27\% were resistant to LVX. Most E. anophelis isolates were

180 resistant to CIP and LVX (92\% and $85 \%$, respectively).

181 A total of 101 (77\%) Elizabethkingia spp. isolates had single-nucleotide mutations in the QRDR

182 of the $g y r A$ gene, whereas no mutations were found in the $g y r B$, parC. or parE gene of these

183 isolates. In contrast, none of the 30 LVX-susceptible Elizabethkingia spp. isolates had mutations

184 in the topoisomerase genes.

185 Among E. anophelis isolates with a gyrA gene mutation, 88 (93.6\%) had a single-nucleotide

186 mutation resulting in Ser83Ile amino acid substitution, whereas a different nucleotide mutation in

1876 isolates resulted in Ser83Arg substitution. The most common single-nucleotide mutation

188 encoding the Ser83Ile substitution was also found in E. meningoseptica and E. miricola isolates.

189 Another single-nucleotide mutation in the gyrA gene, encoding an Asp87Asn substitution, was

190 found in two E. miricola isolates. Our results indicate a strong correlation between the antibiotic 
191 susceptibility profiles of the clinical isolates and their mechanisms of fluoroquinolone resistance.

192 The resistance against CIP and LVX in Elizabethkingia spp. is mainly mediated by a single-

193 nucleotide mutation in the QRDR of the gyrA gene.

194 The 29 isolates without any mutation in $g y r A$, $g y r B$, parC, or parE were completely susceptible

195 or had intermediate susceptibility to CIP (MIC, 0.25-2.00 $\mu \mathrm{g} / \mathrm{ml}$ ) and LVX (MIC, 0.25-2.00

$196 \mu \mathrm{g} / \mathrm{ml}$ ), whereas 102 isolates were fully resistant to CIP with a corresponding MIC range of 32-

$197128 \mu \mathrm{g} / \mathrm{ml}$ and an LVX MIC range of $4-128 \mu \mathrm{g} / \mathrm{ml}$ (Table 3).

198

199 Rapid detection of $g y r A$ mutations using the HRM assay

200 The results of the gyr $A$ gene sequence analysis of Elizabethkingia spp. isolates for the

201 identification of mutations in the QRDR were used to develop an HRM assay that can be used to

202 rapidly scan clinical isolates for typical gyrA gene mutations in 131 isolates of Elizabethkingia

203 species. The HRM assay successfully detected all gyr $A$ mutations in this study, encoding the

204 Ser83Ile, Ser83Arg, and Asp87Asn substitutions. (Fig. 2). The HRM assay results for gyrA

205 genotyping were in complete agreement with our DNA sequencing results without any exception

206 (Table 3).

207

208 RAPD-PCR typing of Elizabethkingia spp. isolates 
209 The 131 Elizabethkingia spp. isolates were clustered into multiple pulsotypes defined by a

210 similarity of $\geq 85 \%$ (Figure 3 ). The widespread pulsotype clusters indicated a lack of temporal or

211 spatial overlap among the infected patients during hospitalization. Specifically, pulsotypes of $E$.

212 meningoseptica and E. miricola isolates harboring a gyrA mutation were found to be distributed

213 among wild type clusters.

214 


\section{Discussion}

216 Elizabethkingia spp. strains represent a group of emerging pathogens, causing infections that are

217 associated with prolonged hospital stays and high mortality rates. In 2015-2016, there was an $E$.

218 anophelis outbreak in Wisconsin, USA, that involved at least 63 patients and 18 deaths

219 (Elbadawi et al. 2016). In addition, another outbreak in Illinois, USA, involving 10 cases with 6

220 deaths has also been reported in 2014-2016 (Navon et al. 2016). Globally, there are numerous

221 sporadic E. meningoseptica nosocomial infection clusters and E. miricola infection case reports

222 in medical centers including in Taiwan. Thus, pathogenic Elizabethkingia spp. strains appear to

223 be opportunistic infectious agents associated with high mortality rates.

224 Quinolones underwent decades of development since the discovery of nalidixic acid in 1962, and

225 quinolone resistance has also existed for decades. Recent studies described LVX-resistant $E$.

226 meningoseptica bacteremia that is associated with an increase in mortality and prolonged

227 hospital stays (Huang et al. 2017; Huang et al. 2018). Appropriate antibiotic use and an effective

228 treatment regime are very important in fighting Elizabethkingia spp. infections. Using the broth

229 microdilution method for MIC testing, we found differences in susceptibility to CIP and LVX

230 among the Elizabethkingia spp. isolates. The discrepancy might be due to the different CLSI

231 breakpoints, $4 \mu \mathrm{g} / \mathrm{ml}$ for CIP and $8 \mu \mathrm{g} / \mathrm{ml}$ for LVX. Previously reported susceptibility profiles of

232 E. anophelis isolates, including from the outbreak in Wisconsin in 2016, indicated that most 
233 isolates were susceptible to quinolones (Lau et al. 2016a; Perrin et al. 2017). In sharp contrast,

234 among our 111 E. anophelis isolates, only 9 and 17 were found to be susceptible to CIP and

235 LVX, respectively.

236 The genetic determinants of quinolone resistance have never been studied in Elizabethkingia spp.

237 Our results revealed that certain single-nucleotide substitutions in gyrA conferred resistance to

238 CIP and LVX in Elizabethkingia spp. The Ser83Ile substitution in GyrA protein was caused by

239 the most prevalent mutation among all isolates, followed by the Ser83Arg or Asp87Asn amino

240 acid substitutions caused by single-nucleotide mutations in E. anophelis or E. miricola. To our

241 knowledge, this is the first report discussing genetic quinolone resistance determinants in

242 Elizabethkingia spp.

243 Bacterial isolates carrying single alterations in QRDRs of DNA gyrase and topoisomerase IV

244 typically exhibit reduced susceptibility to fluoroquinolones, which is considered as the first step

245 in the development of full resistance (Hooper \& Jacoby 2017). The genetic basis for

246 fluoroquinolone resistance appears to be additive, different combinations of distinct resistance

247 mechanisms may result in different MIC (Conley et al. 2018). Other resistant mechanisms such

248 as plasmid-mediated quinolone resistance (PMQR) might also be involved in the quinolone

249 resistance mechanism(Yugendran \& Harish 2016). In our study, resistance to CIP and LVX was

250 associated with single-nucleotide mutations in the QRDR of the gyrA gene in all Elizabethkingia 
251 spp. isolates causing low-level to high-level fluoroquinolone resistance. The level of

252 fluoroquinolone resistance did not correlate with the type of mutation found in the gyrA gene.

253 Other mechanisms typically implicated in fluoroquinolone resistance might be responsible for

254 the differences in CIP and LVX MIC observed among the isolates. Changes in permeability and

255 increased efflux pump activity along with plasmid-encoded resistance determinants cannot be

256 excluded.

257 In this study, we also established a novel rapid HRM assay for detecting gyrA mutations in

258 Elizabethkingia spp. The HRM results were in complete agreement with the DNA sequencing

259 results, indicating that we developed a potentially useful adjunct test for the rapid detection of

260 CIP and LVX resistance in Elizabethkingia spp.

261 Conclusions

262 Our findings demonstrated that the quinolone resistance in Elizabethkingia spp. is associated

263 with mutations in the QRDR of the gyrA gene. However, the level of resistance to quinolones of

264 Elizabethkingia spp. isolates could not be predicted based on the mutations identified in the gyrA

265 gene. This study provided information for further research on the variations of the

266 fluoroquinolone resistance mechanism and potential clinical guidance for infection management. 


\section{Acknowledgments}

269 No.

\section{Ethical approval :}

271 This article does not contain any studies with human participants performed by any of the

272 authors.

\section{Informed consent :}

274 For this type of study formal consent is not required.

275

276 
277

278

279

280

281

282

283

284

285

286

287

288

289

290

291

292

293

294

295

296

297

298

299

300

301

302

303

304

305

306

307

308

309

310

311

\section{References}

Breurec S, Criscuolo A, Diancourt L, Rendueles O, Vandenbogaert M, Passet V, Caro V, Rocha EPC, Touchon M, and Brisse S. 2016. Genomic epidemiology and global diversity of the emerging bacterial pathogen Elizabethkingia anophelis. Scientific Reports 6:30379. 10.1038/srep30379

Chang YC, Lo HH, Hsieh HY, and Chang SM. 2014. Identification and epidemiological relatedness of clinical Elizabethkingia meningoseptica isolates from central Taiwan. $J$ Microbiol Immunol Infect 47:318-323. 10.1016/j.jmii.2013.03.007

Chen S, Soehnlen M, Downes FP, and Walker ED. 2017. Insights from the draft genome into the pathogenicity of a clinical isolate of Elizabethkingia meningoseptica Em3. Stand Genomic Sci 12:56. 10.1186/s40793-017-0269-8

Cheng YH, Perng CL, Jian MJ, Cheng YH, Lee SY, Sun JR, and Shang HS. 2018. Multicentre study evaluating matrix-assisted laser desorption ionisation time-of-flight mass spectrometry for identification of clinically isolated Elizabethkingia species and analysis of antimicrobial susceptibility. Clinical Microbiology and Infection. 10.1016/j.cmi.2018.04.015

Chew K, Cheng B, Lin RTP, and Teo JWP. 2017. Elizabethkingia anophelisis the dominant species found in blood cultures, Singapore. Journal of Clinical Microbiology:17. 10.1128/JCM.01445-17

Chiu CH, Waddingdon M, Greenberg D, Schreckenberger PC, and Carnahan AM. 2000. Atypical Chryseobacterium meningosepticum and meningitis and sepsis in newborns and the immunocompromised, Taiwan. Emerging Infectious Diseases 6:481-486. 10.3201/eid0605.000506

Colapietro M, Endimiani A, Sabatini A, Marcoccia F, Celenza G, Segatore B, Amicosante G, and Perilli M. 2016. BlaB-15, a new BlaB metallo- $\beta$-lactamase variant found in an Elizabethkingia miricola clinical isolate. Diagnostic Microbiology and Infectious Disease 85:195-197. 10.1016/j.diagmicrobio.2015.11.016

Conley ZC, Bodine TJ, Chou A, and Zechiedrich L. 2018. Wicked: The untold story of ciprofloxacin. PLoS Pathogens 14:e1006805. 10.1371/journal.ppat.1006805

Coyle AL. 2017. Elizabethkingia anophelis: Exploring the outbreak of disease in the Midwest. Nursing 47:61-63. 10.1097/01.NURSE.0000512887.67622.84

Doijad S, Glaeser S, Ghosh H, Kämpfer P, and Chakraborty T. 2016. Taxonomic reassessment of the genus Elizabethkingia using whole genome sequencing: Elizabethkingia endophytica Kämpfer et al. 2015 is a later subjective synonym of Elizabethkingia anophelis Kämpfer et al. 2011. International Journal of Systematic and Evolutionary Microbiology. 
312

313

314

315

316

317

318

319

320

321

322

323

324

325

326

327

328

329

330

331

332

333

334

335

336

337

338

339

340

341

342

343

344

345

346

347

10.1099/ijsem.0.001390

Elbadawi LI, Borlaug G, Gundlach K, Monson T, Noble-Wang J, Moulton-Meissner H, Ansari U, Yoder JS, Wise M, McQuiston JR, Kallen A, Davis JP, and Walters M. 2016. A Large and Primarily Community Associated Outbreak of Elizabethkingia anophelis Infections, Wisconsin, 2015-2016. Open Forum Infect Dis 3:9. 10.1093/ofid/ofw195.09

Figueroa Castro CE, Johnson C, Williams M, VanDerSlik A, Graham MB, Letzer D, Ledeboer N, Buchan BW, Block T, Borlaug G, and Munoz-Price LS. 2017. Elizabethkingia anophelis: Clinical Experience of an Academic Health System in Southeastern Wisconsin. Open Forum Infect Dis 4:ofx251. 10.1093/ofid/ofx251

Green ON, Murray P, and Gea-Banacloche JC. 2008. Sepsis caused by Elizabethkingia miricola successfully treated with tigecycline and levofloxacin. Diagnostic Microbiology and Infectious Disease 62:430-432. 10.1016/j.diagmicrobio.2008.07.015

Heisig P. 1996. Genetic evidence for a role of parC mutations in development of high-level fluoroquinolone resistance in Escherichia coli. Antimicrobial Agents and Chemotherapy 40:879-885.

Hooper DC, and Jacoby GA. 2016. Topoisomerase Inhibitors: Fluoroquinolone Mechanisms of Action and Resistance. Cold Spring Harbor Perspectives in Medicine 6. 10.1101/cshperspect.a025320

Hooper DC, and Jacoby GA. 2017. Mechanisms of drug resistance: quinolone resistance. Annals of the New York Academy of Sciences 1354:12-31. 10.1111/nyas.12830

Hsueh PR, Hsiue TR, Wu JJ, Teng LJ, Ho SW, Hsieh WC, and Luh KT. 1996. Flavobacterium indologenes bacteremia: clinical and microbiological characteristics. Clinical Infectious Diseases 23:550-555.

Huang YC, Huang YW, Lin YT, Wang FD, Chan YJ, and Yang TC. 2017. Risk factors and outcome of levofloxacin-resistant Elizabethkingia meningoseptica bacteraemia in adult patients in Taiwan. Eur J Clin Microbiol Infect Dis 36:1373-1380. 10.1007/s10096-0172942-7

Huang YC, Lin YT, and Wang FD. 2018. Comparison of the therapeutic efficacy of fluoroquinolone and non-fluoroquinolone treatment in patients with Elizabethkingia meningoseptica bacteraemia. Int J Antimicrob Agents 51:47-51.

10.1016/j.ijantimicag.2017.05.018

Janda JM, and Lopez DL. 2017. Mini review: New pathogen profiles: Elizabethkingia anophelis. Diagnostic Microbiology and Infectious Disease 88:201-205.

10.1016/j.diagmicrobio.2017.03.007

Jean SS, Lee WS, Chen FL, Ou TY, and Hsueh PR. 2014a. Elizabethkingia meningoseptica: an important emerging pathogen causing healthcare-associated infections. Journal of 
348

349

350

351

352

353

354

355

356

357

358

359

360

361

362

363

364

365

366

367

368

369

370

371

372

373

374

375

376

377

378

379

380

381

382

383

Hospital Infection 86:244-249. 10.1016/j.jhin.2014.01.009

Jean SS, Lee WS, Chen FL, Ou TY, and Hsueh PR. 2014b. Elizabethkingia meningoseptica: an important emerging pathogen causing healthcare-associated infections. J Hosp Infect 86:244-249. 10.1016/j.jhin.2014.01.009

Khodursky AB, Zechiedrich EL, and Cozzarelli NR. 1995. Topoisomerase IV is a target of quinolones in Escherichia coli. Proceedings of the National Academy of Sciences of the United States of America 92:11801-11805.

Kreuzer KN, and Cozzarelli NR. 1979. Escherichia coli mutants thermosensitive for deoxyribonucleic acid gyrase subunit A: effects on deoxyribonucleic acid replication, transcription, and bacteriophage growth. Journal of Bacteriology 140:424-435.

Lau SK, Chow WN, Foo CH, Curreem SO, Lo GC, Teng JL, Chen JH, Ng RH, Wu AK, Cheung IY, Chau SK, Lung DC, Lee RA, Tse CW, Fung KS, Que TL, and Woo PC. 2016a. Elizabethkingia anophelis bacteremia is associated with clinically significant infections and high mortality. Scientific Reports 6:26045. 10.1038/srep26045

Lau SKP, Chow W-N, Foo C-H, Curreem SOT, Lo G, Teng JLL, Chen JHK, Ng RHY, Wu AKL, Cheung IYY, Chau SKY, Lung DC, Lee RA, Tse CWS, Fung KSC, Que T-L, and Woo PCY. 2016b. Elizabethkingia anophelis bacteremia is associated with clinically significant infections and high mortality. Scientific Reports 6:26045. 10.1038/srep26045

Lin J-NN, Lai C-HH, Yang C-HH, Huang Y-HH, Lin H-FF, and Lin H-HH. 2017. Comparison of four automated microbiology systems with 16S rRNA gene sequencing for identification of Chryseobacterium and Elizabethkingia species. Scientific Reports 7:13824. 10.1038/s41598-017-14244-9

Navon L, Clegg WJ, Morgan J, Austin C, McQuiston JR, Blaney DD, Walters M, MoultonMeissner H, and Nicholson A. 2016. Notes from the Field: Investigation of Elizabethkingia anophelis Cluster - Illinois, 2014-2016. MMWR Morbidity and Mortality Weekly Report 65:1380-1381. 10.15585/mmwr.mm6548a6

Nicholson AC, Gulvik CA, Whitney AM, Humrighouse BW, Graziano J, Emery B, Bell M, Loparev V, Juieng P, Gartin J, Bizet C, Clermont D, Criscuolo A, Brisse S, and McQuiston JR. 2017. Revisiting the taxonomy of the genus Elizabethkingia using wholegenome sequencing, optical mapping, and MALDI-TOF, along with proposal of three novel Elizabethkingia species: Elizabethkingia bruuniana sp. nov., Elizabethkingia ursingii sp. nov., and Elizabethkingia occulta sp. nov. Antonie Van Leeuwenhoek:1-18. 10.1007/s 10482-017-0926-3

Opota O, Diene SM, Bertelli C, Prod'hom G, Eckert P, and Greub G. 2017. Genome of the carbapenemase-producing clinical isolate Elizabethkingia miricola EM_CHUV and comparative genomics with Elizabethkingia meningoseptica and Elizabethkingia 
384

385

386

387

388

389

390

391

392

393

394

395

396

397

398

399

400

401

402

403

404

405

406

407

408

409

410

411

412

413

414

415

416 anophelis: evidence for intrinsic multidrug resistance trait of emerging pathogens. International Journal of Antimicrobial Agents 49:93-97. 10.1016/j.ijantimicag.2016.09.031

Perrin A, Larsonneur E, Nicholson AC, Edwards DJ, Gundlach KM, Whitney AM, Gulvik CA, Bell ME, Rendueles O, Cury J, Hugon P, Clermont D, Enouf V, Loparev V, Juieng P, Monson T, Warshauer D, Elbadawi LI, Walters M, Crist MB, Noble-Wang J, Borlaug G, Rocha EPC, Criscuolo A, Touchon M, Davis JP, Holt KE, McQuiston JR, and Brisse S. 2017. Evolutionary dynamics and genomic features of the Elizabethkingia anophelis 2015 to 2016 Wisconsin outbreak strain. Nature Communications 8. $10.1038 /$ ncomms 15483

Shaohua H, Tao J, Xia Z, Yajun Z, Zhengjun Y, Youxi W, Sishou Z, Mingxi W, Desong M, and Shicheng C. 2017. Elizabethkingia anophelis Isolated from Patients with Multiple Organ Dysfunction Syndrome and Lower Respiratory Tract Infection: Report of Two Cases and Literature Review. Frontiers in Microbiology 8:382. 10.3389/fmicb.2017.00382

Syn CK, and Swarup S. 2000. A scalable protocol for the isolation of large-sized genomic DNA within an hour from several bacteria. Analytical Biochemistry 278:86-90. 10.1006/abio.1999.4410

Yoshida H, Bogaki M, Nakamura M, and Nakamura S. 1990. Quinolone resistance-determining region in the DNA gyrase gyrA gene of Escherichia coli. Antimicrobial Agents and Chemotherapy 34:1271-1272.

Yoshida H, Bogaki M, Nakamura M, Yamanaka LM, and Nakamura S. 1991. Quinolone resistance-determining region in the DNA gyrase gyrB gene of Escherichia coli. Antimicrob Agents Chemother 35:1647-1650.

Yugendran T, and Harish BN. 2016. High incidence of plasmid-mediated quinolone resistance genes among ciprofloxacin-resistant clinical isolates of Enterobacteriaceae at a tertiary care hospital in Puducherry, India. PeerJ 4:e1995. 10.7717/peerj.1995

Zdziarski P, Paściak M, Rogala K, Korzeniowska-Kowal A, and Gamian A. 2017. Elizabethkingia miricola as an opportunistic oral pathogen associated with superinfectious complications in humoral immunodeficiency: a case report. $B M C$ Infectious Diseases 17:763. 10.1186/s12879-017-2886-7 


\section{$418 \quad$ Figure legends}

419 Figure 1. Fluoroquinolone MIC values of Elizabethkingia species. (A) E. anophelis isolates

420 (n=111). (B) E. meningoseptica isolates (n=9). (C) E. miricola isolates $(\mathrm{n}=11)$. Each symbol $(\diamond$,

$421 \square, \Delta, \circ)$ represents one isolate.

422 CIP, ciprofloxacin; LVX, levofloxacin; S, susceptible; I/R, intermediate/resistant

423 Susceptibility ( $\leq$ value), intermediate and resistance ( $\geq$ value) breakpoints defined by CLSI

424 (2016): $1 \mu \mathrm{g} / \mathrm{ml}, 2 \mu \mathrm{g} / \mathrm{ml}$ and $4 \mu \mathrm{g} / \mathrm{ml}$ for CIP; $2 \mu \mathrm{g} / \mathrm{ml}, 4 \mu \mathrm{g} / \mathrm{ml}$ and $8 \mu \mathrm{g} / \mathrm{ml}$ for LVX.

$425 * *: \mathrm{P}<0.01 ; * * *: \mathrm{P}<0.001 ; * * * *: \mathrm{P}<0.0001$.

426

427

428 Figure 2. Representative HRM analysis of gyrA mutation and wild-type in Elizabethkingia

429 species isolates. (A) gyrA wild-type (n=2) and gyrA mutation (n=28) Elizabethkingia anophelis

430 isolates. (B) gyrA wild-type $(\mathrm{n}=5)$ and gyrA mutation $(\mathrm{n}=4)$ Elizabethkingia meningoseptica

431 isolates. (C) gyrA wild-type (n=8) and gyrA mutation (n=3) Elizabethkingia miricola isolates.

432 WT: wild-type. Blue lines represent gyrA wild-type isolates, red lines and green lines represent

433 gyrA mutation isolates, orange lines represent no template control. 
436 Figure 3. RAPD PCR dendrogram of the Elizabethkingia spp. isolates investigated in this study.

437 (A) Clustering dendrogram of E. anophelis isolates (n=111). (B) Clustering dendrogram of $E$.

438 meningoseptica isolates $(\mathrm{n}=9)$. (C) Clustering dendrogram of E. miricola isolates $(\mathrm{n}=11)$. E.A: E.

439 anophelis E.M: E. meningoseptica; E.m: E. miricola. Black triangles represent clusters with

440 multiple isolates possessing the same gyrA mutations. Black circles represent monoisolate

441 clusters with gyrA mutations. The dashed line represents the similarity level (85\%) used in the

442 clusters definition.

443

444 
Table $\mathbf{1}$ (on next page)

Primer sequences used in this study 
Table 1. Primer sequences used in this study

2

Primer sequences used to amplify gyrA, gyrB, parC, and parE genes in Elizabethkingia spp.

\begin{tabular}{|c|c|c|c|}
\hline Primer name & Sequence $\left(5^{\prime} \rightarrow 3^{\prime}\right)$ & $\begin{array}{l}\text { Annealing } \\
\text { temperature }\left({ }^{\circ} \mathrm{C}\right)\end{array}$ & $\begin{array}{l}\text { Product } \\
\text { Size (bp) }\end{array}$ \\
\hline gyrA-E.species-F* & AGC CCG TTG TTT AAA TCC TGA A & \multirow[b]{2}{*}{50} & \multirow{2}{*}{743} \\
\hline gyrA-E.species-R & CCC TGT TGG GAA GTC TGG TG & & \\
\hline gyrB-E.species-F & GAT AAT TTC CTT CAT AAA GAG CC & \multirow{4}{*}{48} & \multirow{4}{*}{$\begin{array}{l}905 \\
896 \\
903\end{array}$} \\
\hline gyrB-E.anophelis-R & CAT TGC CAT ACT GAG CTT GT & & \\
\hline gyrB-E.menigospetica-R & TCG AAG TGT TTG CTT TGT CA & & \\
\hline gyrB-E.miricola-R & GCG TTG TCA TAC TGA ACT TG & & \\
\hline parC-E.species- $F^{* *}$ & GCT CAG TAT GGC AAT GCT AAA A & \multirow{4}{*}{50} & \multirow{4}{*}{785} \\
\hline parC-E.species-R & TTG CTC TTA CCT TAC CGC CG & & \\
\hline parC-E.menigospetica-F & TGA CCG GAT CAA CCG AAG TC & & \\
\hline parC-E.menigospetica-R & CAG GTC GCC TGT TGT TTT GG & & \\
\hline parE-E.species-F & GTA TTC AGT TTA AAA GGT AAA CC & \multirow{4}{*}{48} & \multirow{4}{*}{$\begin{array}{l}694 \\
657 \\
683\end{array}$} \\
\hline parE-E.anophelis-R & GAA TAT ATT GGG CTT CGA CA & & \\
\hline parE-E.menigospetica-R & ACT GAA CTT AGT TTG CCA TAA G & & \\
\hline parE-E.miricola-R & AGA AAT CGA CAT ATT CAG AGG T & & \\
\hline
\end{tabular}

3 * gyrA-E.species-F and gyrA-E.species-R could amplify all Elizabethkinga species gyrA gene (including E. anohpelis, E. menigospetica and E. miricola)

$4 \quad$ "* parC-E.species-F and parC-E.species-R could amplify both E. anohpelis and E. miricola parC gene

5

6 Primer sequences used for RAPD PCR. 


\begin{tabular}{lll}
\hline Primer name & Sequence & Target \\
\hline OPA-10 & GTG ATC GCA G & E. anophelis \\
\hline OPB-15 & GGA GGG TGT T & $\begin{array}{l}\text { E. menigospetica } \\
\text { E. miricola }\end{array}$ \\
\hline
\end{tabular}

7 Primer sequences used for fluoroquinolone HRM analysis assays.

\begin{tabular}{llcc}
\hline Primer name & Sequence $\left(5^{\prime} \rightarrow 3^{\prime}\right)$ & $\begin{array}{c}\text { Annealing } \\
\text { temperature }\left({ }^{\circ} \mathrm{C}\right)\end{array}$ & $\begin{array}{c}\text { Product } \\
\text { Size (bp) }\end{array}$ \\
\hline gyrA-HRM-E.species-F & TGC CAG AAT TGT TGG AGA TG & & \\
\cline { 1 - 2 } gyrA-HRM-E.anophelis-R & TAG CGC AGA GAC CAT GAC TG & & 50 \\
\cline { 1 - 2 } gyrA-HRM-E.menigospetica-R & GTG CCA TAC GCA CCA TAG CA & & 102 \\
\cline { 1 - 2 } gyrA-HRM-E.miricola-R & CTG TGC CAT ACG CAC CAT AG & & 83 \\
\hline
\end{tabular}

8 


\section{Table 2 (on next page)}

Antimicrobial susceptibility of ciprofloxacin/levofloxacin and mutation position detected in the gyrase or topoisomerase IV genes of Elizabethkingia species isolates 
1 Table 2. Antimicrobial susceptibility of ciprofloxacin/levofloxacin and mutation position detected in the gyrase or topoisomerase IV genes of 2 Elizabethkingia species isolates

3



4

$5 \quad$ "CIP, ciprofloxacin; LVX, levofloxacin. Susceptibility ( $\leq$ value) and resistance ( $\geq$ value) breakpoints defined by CLSI (2016): $1 \mu \mathrm{g} / \mathrm{ml}$ and $4 \mu \mathrm{g} / \mathrm{ml}$ for ciprofloxacin, $2 \mu \mathrm{g} / \mathrm{ml}$ and $8 \mu \mathrm{g} / \mathrm{ml}$ for 6 levofloxacin. 


\section{Table 3 (on next page)}

Alterations in gyrA genes detected by HRM assay and confirmed by DNA sequence analysis in Elizabethkingia spp. isolates. 
1 Table 3. Alterations in gyrA genes detected by HRM assay and confirmed by DNA sequence analysis in Elizabethkingia spp. isolates.

\begin{tabular}{ccccc}
\hline \multirow{2}{*}{ Species } & \multirow{2}{*}{ Number of isolate } & \multicolumn{2}{c}{ Mutation detected by HRM } & Confirmation by sequencing \\
\cline { 2 - 5 } & & $\boldsymbol{g y r} \mathbf{A 8 3}$ & $\boldsymbol{g y r A 8 7}$ & $\boldsymbol{g y r} \boldsymbol{A}$ gene \\
\hline \multirow{2}{*}{ E. anophelis } & 94 & Mutation & None & Ser83Ile/Ser83Arg \\
\cline { 2 - 5 } & 17 & None & None & No mutation \\
\hline \multirow{2}{*}{ E. menigoseptica } & 5 & Mutation & None & Ser83Ile \\
\cline { 2 - 5 } & 4 & None & None & No mutation \\
\hline \multirow{2}{*}{ E. miricola } & 1 & Mutation & None & Ser83Ile \\
\cline { 2 - 5 } & 2 & None & Mutation & Asp87Asn \\
\hline & 8 & None & None & No mutation \\
\hline
\end{tabular}




\section{Figure 1 (on next page)}

Fluoroquinolone MIC values of Elizabethkingia species.

(A) E. anophelis isolates $(n=111)$. (B) E. meningoseptica isolates $(n=9)$. (C) E. miricola isolates $(n=11)$. Each symbol $(\diamond, \square, \Delta, O)$ represents one isolate. CIP, ciprofloxacin; LVX, levofloxacin; S, susceptible; I/R, intermediate/resistant Susceptibility ( $\leq$ value), intermediate and resistance ( $\geq$ value) breakpoints defined by CLSI (2016): $1 \mu \mathrm{g} / \mathrm{ml}, 2 \mu \mathrm{g} / \mathrm{ml}$ and $4 \mu \mathrm{g} / \mathrm{ml}$ for CIP; $2 \mu \mathrm{g} / \mathrm{ml}, 4 \mu \mathrm{g} / \mathrm{ml}$ and $8 \mu \mathrm{g} / \mathrm{ml}$ for LVX. **: $\mathrm{P}<0.01$; ***: $\mathrm{P}<0.001$; ****: $\mathrm{P}<0.0001$. 

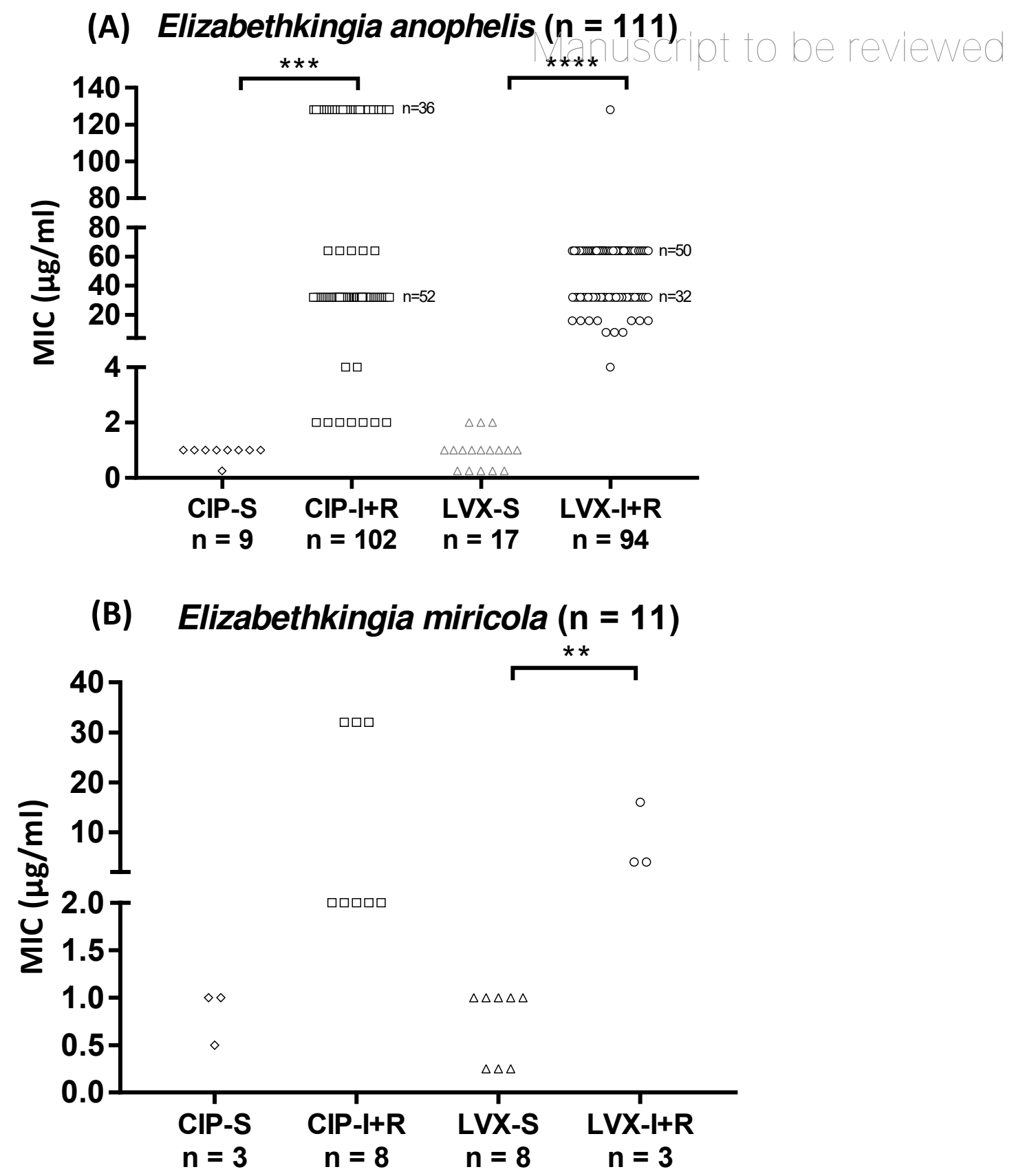

(C) Elizabethkingia meningoseptica $(\mathrm{n}=9)$

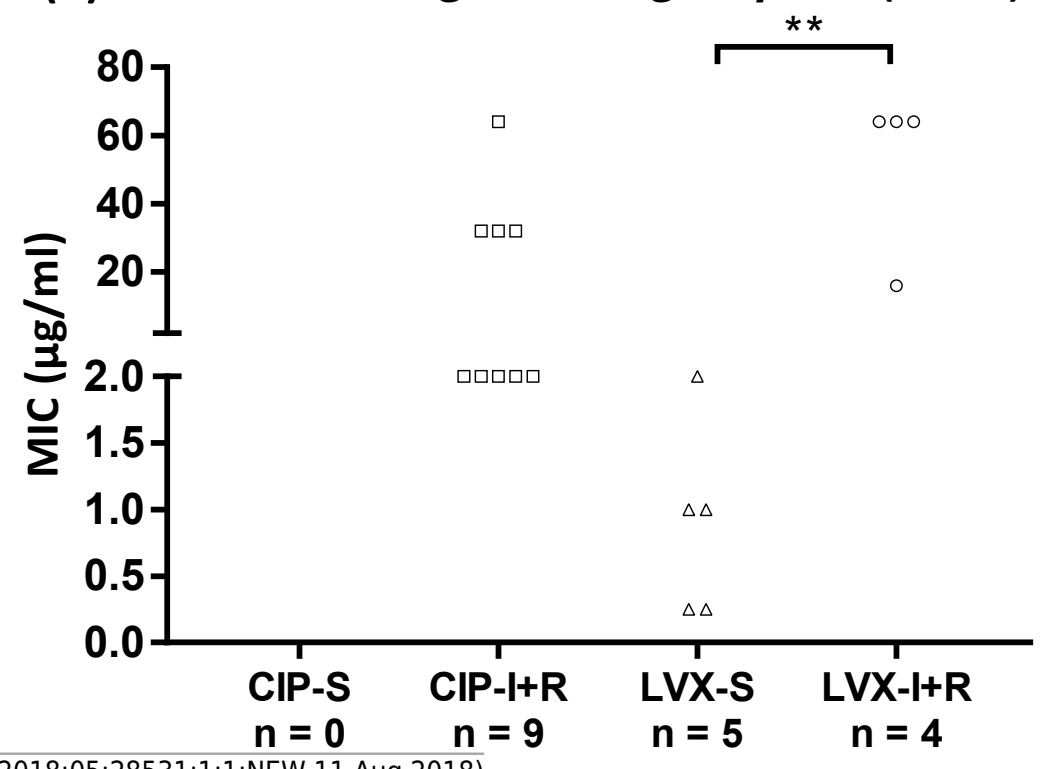




\section{Figure 2}

Representative HRM analysis of gyrA mutation and wild-type in Elizabethkingia species isolates.

(A) gyrA wild-type $(n=2)$ and gyrA mutation $(n=28)$ Elizabethkingia anophelis isolates. (B) gyrA wild-type $(n=5)$ and gyrA mutation $(n=4)$ Elizabethkingia meningoseptica isolates. (C) gyrA wild-type $(n=8)$ and gyrA mutation $(n=3)$ Elizabethkingia miricola isolates. WT: wildtype. Blue lines represent gyrA wild-type isolates, red lines and green lines represent gyrA mutation isolates, orange lines represent no template control. 



(B)
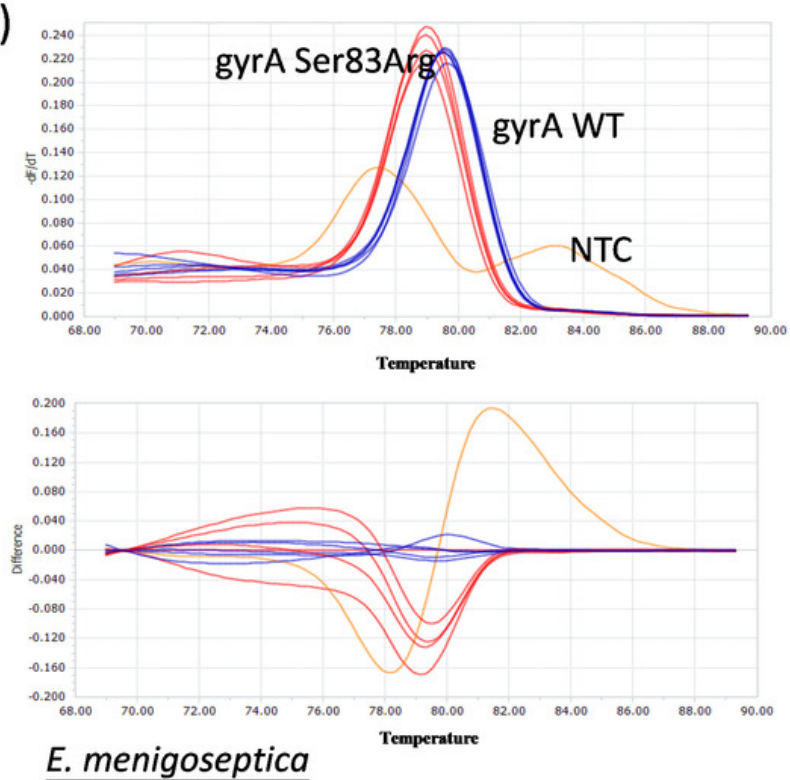

(C)
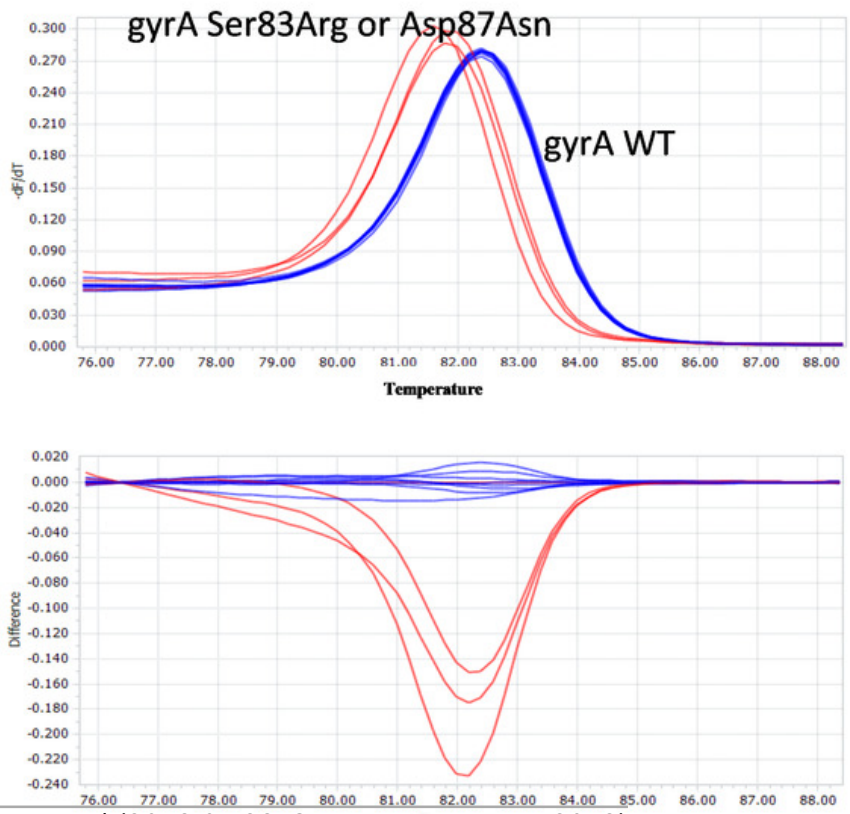


\section{Figure 3}

RAPD PCR dendrogram of the Elizabethkingia spp. isolates investigated in this study.

(A) Clustering dendrogram of $E$. anophelis isolates $(n=111)$. (B) Clustering dendrogram of $E$. meningoseptica isolates $(n=9)$. (C) Clustering dendrogram of E. miricola isolates $(n=11)$. E.A: E. anophelis E.M: E. meningoseptica; E.m: E. miricola. Black triangles represent clusters with multiple isolates possessing the same gyrA mutations. Black circles represent monoisolate clusters with gyrA mutations. The dashed line represents the similarity level (85\%) used in the clusters definition.

(A)

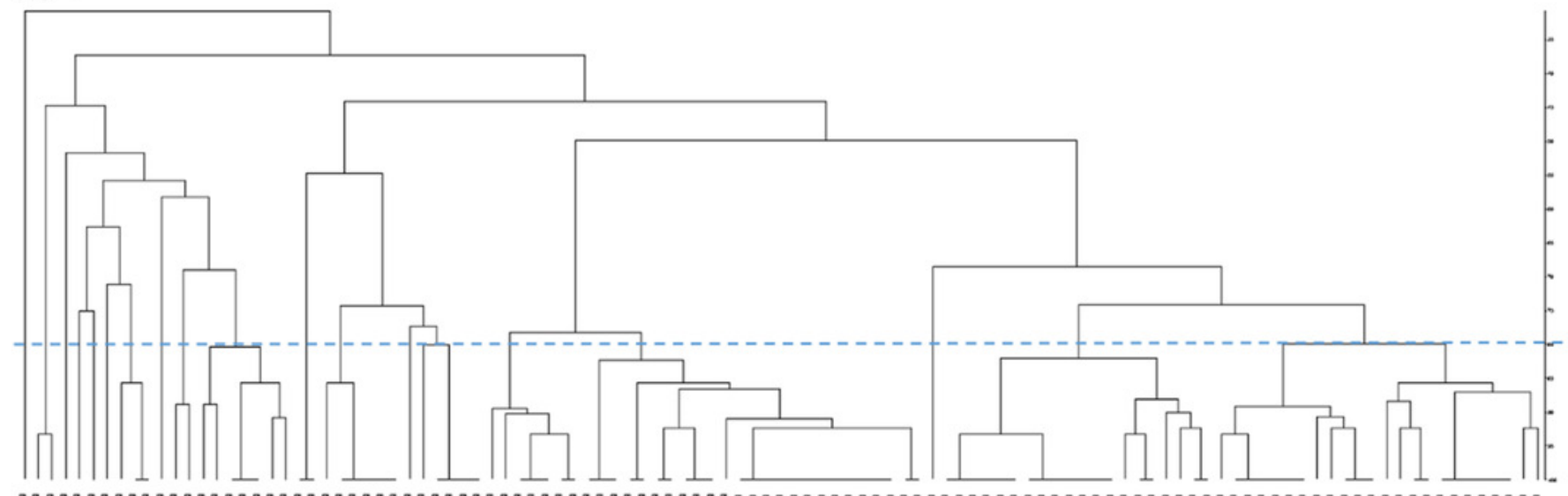

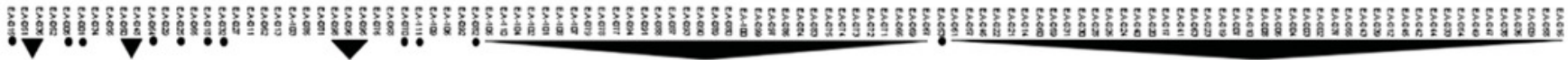

E.A: E. anophelis

(B)

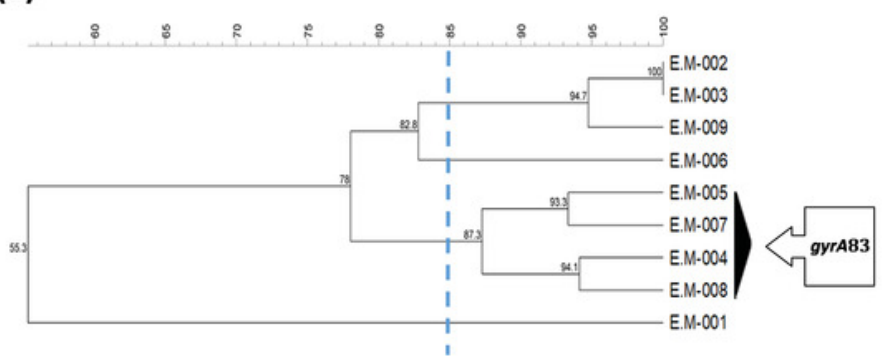

E.M: E. menigoseptica
(C)



E.m: E. miricola 